\title{
Perspective
}

PERSPECTIVE Actualité en histoire de l'art

Comptes rendus | 2012

\section{Erma Hermens éd., On the Trail of Bosch and Bruegel: \\ For Paintings United under Cross-Examination, Copenhague, Archetype Publications, 2012}

Frédéric Elsig

\section{(2) OpenEdition}

Édition électronique

URL : http://journals.openedition.org/perspective/3335

DOI : 10.4000/perspective.3335

ISSN : 2269-7721

Éditeur

Institut national d'histoire de l'art

Référence électronique

Frédéric Elsig, «Erma Hermens éd., On the Trail of Bosch and Bruegel: For Paintings United under CrossExamination, Copenhague, Archetype Publications, 2012 », Perspective [En ligne], Comptes rendus, mis en ligne le 02 septembre 2013, consulté le 01 octobre 2020. URL : http://journals.openedition.org/ perspective/3335; DOI : https://doi.org/10.4000/perspective.3335

Ce document a été généré automatiquement le 1 octobre 2020. 


\section{Erma Hermens éd., On the Trail of} Bosch and Bruegel: For Paintings United under Cross-Examination, Copenhague, Archetype Publications, 2012

Frédéric Elsig

\section{RÉFÉRENCE}

Erma Hermens éd., On the Trail of Bosch and Bruegel: For Paintings United under CrossExamination, Copenhague, Archetype Publications, 2012. 
Ce volume réunit plusieurs contributions qui croisent différentes compétences sur le Jésus chassant les marchands du Temple, une composition boschienne connue à travers quatre versions, conservées à Genève (collection privée), Copenhague, Talinn et Glasgow. Publié à l'occasion de la restauration de l'exemplaire de Copenhague, il se fonde sur la comparaison matérielle, iconographique et stylistique des quatre tableaux pour mieux comprendre le processus créateur, selon une démarche exemplairement mise en œuvre dans la mémorable exposition Bruegel Enterprise (2001-2002). À en juger par l'examen stylistique et

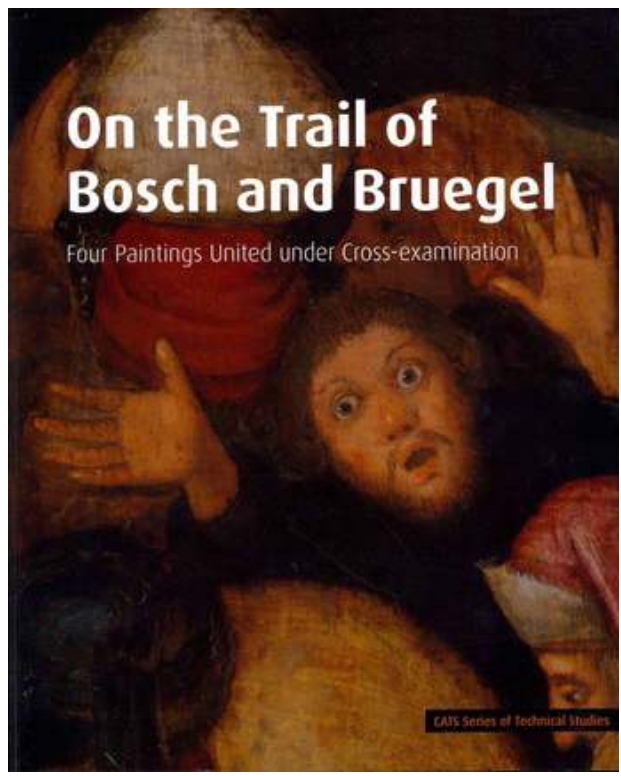
dendrochronologique, les exemplaires de Copenhague et de Talinn pourraient avoir été peints durant les années 1570 dans le cercle de Pieter I Bruegel. Reflètent-ils pour autant une invention de ce dernier ? La version genevoise, la meilleure du groupe, tend à l'exclure, dans la mesure où elle se situe autour de 1540 et peut être rapprochée du Banquet burlesque de Bilbao, assigné à Jan Mandyn ou à l'atelier Verbeeck, comme le note Paul Vandenbroeck. La composition dériverait-elle alors d'une idée de Bosch luimême? Elle serait plutôt due à un suiveur qui pastiche le répertoire boschien. L'exemplaire de Glasgow, qui l'adapte à un format vertical, franchit un pas supplémentaire en cherchant à se faire passer pour une œuvre de Bosch. D’après sa signature ostentatoire, son aspect archaïsant et ses faux bords non peints, il constitue de toute évidence une falsification produite au milieu du Xvi siècle, au moment le plus fort du succès commercial de Bosch, comme l'a bien relevé Bernard Vermet. L'ouvrage apporte ainsi une contribution concrète à la connaissance des suiveurs de Bosch, un thème qui fera l'objet d'une importante exposition organisée à l'occasion du cinq centième anniversaire de la mort du peintre, à Bois-le-Duc en 2016. 